\title{
Audiogenic seizures in mice: Asymmetries of the preconvulsive running pattern and subsequent seizure
}

\author{
HOWARD M. REID \\ State University College at Buffalo, Buffalo, New York \\ and \\ ROBERT L. COLLINS \\ Jackson Laboratory, Bar Harbor, Maine
}

\begin{abstract}
Asymmetries in the progression of unilaterally and bilaterally induced audiogenic seizures were examined in DBA/2J and SJL/J mice. Both strains were found to exhibit consistent asymmetries in direction(s) of running as well as in the side of fall during a convulsion. This correspondence suggests that the bursts of running are an integral part of an audiogenic seizure. The incorporation of information on asymmetries of the locomotor prelude in future studies should prove valuable for understanding the physiological mechanisms of audiogenic seizure.
\end{abstract}

The audiogenic seizures of experimental animals continues to be one of the most extensively studied models of stimulus-induced, or reflex, epilepsies. Generally, the attention of investigators engaged in such research is directed at observing the presence or absence of landmarks in the emerging seizure and summarizing the temporal parameters of the phases of the convulsion. Because there has existed a lack of uniformity for the naming of stages in the seizure sequence, a second generation, standardized nomenclature has been proposed recently, whose adoption should aid investigators in interrelating their findings (Schreiber, Lehmann, Ginsburg, \& Fuller, 1980). Even if we adopt these new naming rules, it is of interest to note that there exists another set of clearly observable and fascinating features of audiogenic seizure-its asymmetries-whose incorporation into our research strategies may enable us to approach new and potentially important research questions. By means of this report we hope to reacquaint the reader with certain asymmetries of audiogenic seizure observed in mice and to present evidence for a new asymmetry in the preconvulsive motor pattern.

This work was supported in part by Research Grants GM 23618 from the National Institute of General Medical Sciences, BMS 15966 from the National Science Foundation, and 121-7194-A from the State University of New York Research Foundation. The Jackson Laboratory is fully accredited by the American Association for Accreditation of Laboratory Animal Care. Howard M. Reid's mailing address is: Department of Psychology, State University College at Buffalo, Buffalo, New York 14222. Robert L. Collins's mailing address is: Jackson Laboratory, Bar Harbor, Maine 04609.
Studies of asymmetric susceptibility to soundinduced convulsion often utilize mice from strains whose members are initially resistant to audiogenic seizure, such as $\mathrm{SJL} / \mathrm{J}$. These mice become susceptible following a brief exposure to intense auditory stimulation (Fuller \& Collins, 1968a; Henry, 1967; Iturrian \& Fink, 1969). If, however, the stimulation is limited to one ear by blocking the other with glycerine, subsequent susceptibility is limited to the side exposed initially (Fuller \& Collins, 1968b). Thus, unilateral exposure to a sensitizing stimulus results in an asymmetrically susceptible subject.

The audiogenic seizures occurring in mice that have been rendered unilaterally susceptible to stimulation have been found to be asymmetric. During the convulsion, these mice fall upon the side on which the nonsensitive ear lies (Ward \& Collins, 1971). A similar effect has also been noted in bilaterally susceptible animals. Specifically, subjects that are bilaterally susceptible, due to either genetic background, as in mice of the $\mathrm{DBA} / 2 \mathrm{~J}$ strain, or to prior exposure, fall upon the blocked ear when a seizure is unilaterally induced (Ward \& Collins, 1971). Immediately following the convulsion, these subjects will seize again if stimulated through the previously untested ear. Depending upon the strain employed (Ward, 1971), stimulation of the previously tested ear is ineffective for a period ranging from a few minutes to more than an hour.

Whereas $\mathrm{DBA} / 2 \mathrm{~J}$ and $\mathrm{SJL} / \mathrm{J}$ inbred strains differ in initial susceptibility, mice of both strains can undergo two distinct forms of audiogenic seizure. The first form of seizure is rapid, is preceded by a single running bout, and, particularly in $\mathrm{DBA} / 2 \mathrm{~J}$ mice, reaches a tonic level culminating in respiratory 
failure and death. The second form of seizure requires a longer period of auditory stimulation, is characteristically preceded by two running episodes, and usually attains only a clonic level of violence (Collins, 1972; Fuller \& Smith, 1953). Although an association between the direction of run immediately preceding a convulsion and the convulsive asymmetry itself was suggested following an examination of filmed records (Ward \& Collins, 1971), this relationship has not been experimentally verified. The following experiments were designed to determine whether the uniphasic and biphasic bursts of running preceding audiogenic seizures are predictably asymmetric and, if so, whether the asymmetries exhibited by mice from strains that are initially susceptible to audiogenic seizure are similar to those from strains requiring prior sensitization before becoming susceptible.

\section{METHOD}

The two experiments employed DBA/2J and SJL/J mice obtained from the Animal Resources Division of the Jackson Laboratory at $21 \pm 3$ and $20 \pm 3$ days of age, respectively. The apparatus consisted of a sound deadened box within which was centered an electric bell $(10.5 \mathrm{~cm}$ in diameter, sound level approximately $90 \mathrm{~dB}) 41 \mathrm{~cm}$ above the floor of a clear, plastic cylinder ( $30.5 \mathrm{~cm}$ in diameter, $30 \mathrm{~cm}$ in height).

In Experiment 1, 175 mice from the seizure-susceptible DBA/2J strain were tested at $22 \pm 3$ days of age by being exposed individually to the ringing of the electric bell for a maximum of $60 \mathrm{sec}$. When a seizure occurred, the bell was turned off at the beginning of the clonic phase. Of these mice, 74 were tested with either the left or right ear blocked with glycerine and 80 with neither ear blocked; 21 mice had both ears closed to serve as controls for the effectiveness of the glycerine block.

In Experiment 2, 186 mice from the initially seizure-resistant $\mathrm{SJL} / \mathrm{J}$ strain were sensitized individually at $21 \pm 3$ days of age by being exposed to the ringing of the electric bell for $30 \mathrm{sec}$. Of these, 93 mice were sensitized with either the left or right ear blocked with glycerine, and 93 were exposed with neither ear blocked. Four subjects had to be discarded: One bilaterally and two unilaterally sensitized animals died before testing, and one unilaterally stimulated subject seized during sensitization. An additional 22 mice had both ears blocked and served as controls for the effectiveness of the glycerine treatment. Immediately following the auditory stimulation, each unblocked ear was filled with glycerine to prevent any asymmetric effect due to procedures other than exposure to the bell. Testing consisted of individually exposing the $\mathrm{SJL} / \mathrm{J}$ mice at $24 \pm 3$ days of age to the ringing of the bell for $60 \mathrm{sec}$ or until initiation of a clonic convulsion. Subjects serving as controls for the glycerine block were tested with both ears open. Subjects in the experimental groups were tested with either a single sensitized ear open or with both ears open.

\section{RESULTS}

None of the $21 \mathrm{DBA} / 2 \mathrm{~J}$ mice that served as controls for the glycerine block in Experiment 1 seized, whereas $41(55 \%)$ of the unilaterally tested mice and $79(99 \%)$ of the bilaterally tested mice seized. Virtually all of the unilaterally induced seizures were of clonic violence, whereas most of the bilaterally tested subjects had tonic seizures resulting in respiratory failure and death. Two distinct patterns of convulsions were noted in DBA/ $2 \mathrm{~J}$ mice. The first form consisted of a rapid convulsion (occurring within $30 \mathrm{sec}$ of the onset of the bell) that, with rare exception, was preceded by only a single running bout. The second form was a slower seizure (occurring between 30 and $60 \mathrm{sec}$ after the onset of the bell) that was usually preceded by two running bouts, one before $30 \mathrm{sec}$ had elapsed and the other immediately preceding the seizure. Between the running bouts of a slow seizure, mice remained essentially motionless or engaged in grooming behavior for a period of at least $10 \mathrm{sec}$.

Unilaterally induced seizures in DBA/ $2 \mathrm{~J}$ mice were found to be asymmetric. Mice with seizures driven by stimulating the right ear fell on the left side (19 of the 22 subjects), whereas mice with seizures driven by stimulating the left ear consistently fell on the right side (19 of 19 subjects; $\chi^{2}=30.58, \mathrm{p}<.001$ ). Furthermore, DBA/2J mice tested with the right ear open circled counterclockwise during both running bursts preceding a "slow" seizure as well as the single bout preceding a "fast" seizure, whereas mice tested with the left ear open circled clockwise. Columns 1 and 2 of Table 1 include the data for unilaterally tested mice that had at least one running episode with an identified direction and that fell to the left or right. In a few instances the direction of a run could not be unequivocally classified. As a consequence, the totals for first and second runs are not always equal in Table 1.

Seventy-eight of the 79 bilaterally elicited seizures in DBA/2J mice were "rapid" and were preceded by only one running bout. Eight subjects had to be discarded because their seizures did not permit un-

Table 1

Summary of the Relationships Between the Direction of Run and Side of Fall in Unilaterally and Bilaterally Tested DBA/2J Mice

\begin{tabular}{|c|c|c|c|c|c|c|c|}
\hline & & \multicolumn{6}{|c|}{ Side of Fall } \\
\hline & & \multicolumn{2}{|c|}{$\begin{array}{c}\text { Right Ear } \\
\text { Open } \\
\end{array}$} & \multicolumn{2}{|c|}{$\begin{array}{c}\text { Left Ear } \\
\text { Open } \\
\end{array}$} & \multicolumn{2}{|c|}{$\begin{array}{c}\text { Both Ears } \\
\text { Open }\end{array}$} \\
\hline & & $\mathrm{L}$ & $\mathbf{R}$ & $\mathrm{L}$ & $\mathbf{R}$ & $\mathrm{L}$ & $\mathbf{R}$ \\
\hline DB1 & $\begin{array}{l}\mathrm{C} \\
\mathrm{CC}\end{array}$ & $\begin{array}{l}1 \\
7\end{array}$ & $\begin{array}{l}0 \\
0\end{array}$ & $\begin{array}{l}0 \\
0\end{array}$ & $\begin{array}{l}4 \\
0\end{array}$ & $\begin{array}{l}0 \\
1\end{array}$ & $\begin{array}{l}0 \\
0\end{array}$ \\
\hline DB2 & $\begin{array}{l}\mathrm{C} \\
\mathrm{CC}\end{array}$ & $\begin{array}{l}0 \\
6\end{array}$ & $\begin{array}{l}0 \\
0\end{array}$ & $\begin{array}{l}0 \\
0\end{array}$ & $\begin{array}{l}4 \\
0\end{array}$ & $\begin{array}{l}0 \\
1\end{array}$ & $\begin{array}{l}0 \\
0\end{array}$ \\
\hline DU & $\begin{array}{l}\mathrm{C} \\
\mathrm{CC}\end{array}$ & $\begin{array}{l}3 \\
6\end{array}$ & $\begin{array}{l}1 \\
2\end{array}$ & $\begin{array}{l}0 \\
0\end{array}$ & $\begin{array}{r}10 \\
0\end{array}$ & $\begin{array}{l}11 \\
26\end{array}$ & $\begin{array}{l}20 \\
13\end{array}$ \\
\hline
\end{tabular}

Note- $L, R$, and $B$ signify left, right, and both, respectively; $C$ and $C C$ denote clockwise and counterclockwise, respectively. The upper four rows of the table present relationships for each run of a biphasic or "slow" audiogenic seizure, a convulsion occurring after $30 \mathrm{sec}$ of auditory stimulation; $D B 1=$ direction of first run of biphasic seizure, and $D B 2=$ direction of second run of biphasic seizure. The bottom two rows of the table present data for the single run of uniphasic or "fast" seizures, convulsions occurring within $30 \mathrm{sec}$ of auditory stimulation; $D U=$ direction of run of uniphasic seizure. 
equivocal identification of the direction of run and/or side of fall. The data for the remaining subjects are shown in column 3 of Table 1. The results indicate that mice that run counterclockwise tend to fall to their left, while mice that run clockwise tend to fall to their right $\left(\chi^{2}=6.74, p<.01\right)$. This is the same relationship that was found for DBA/2J mice tested unilaterally.

$\mathrm{SJL} / \mathrm{J}$ mice were employed in Experiment 2 to determine the extent to which findings based on the DBA/2J strain would generalize to mice requiring sensitization before becoming susceptible to convulsion. Control subjects for the effectiveness of the glycerine block during sensitization were tested with both ears open. Only 1 of these 22 subjects seized, whereas 100 of 182 experimental subjects tested with either one or both ears open seized. Virtually all seizures were of clonic violence.

The audiogenic seizures observed in Experiment 2 were asymmetric. Whereas mice primed with the right ear open fell with the left side down $(22$ of 25 subjects with a clearly defined side of fall), mice primed with the left ear open fell on the right side during seizure (13 of 15 subjects with a clearly defined side of fall; $\chi^{2}=21.78, p<.001$ ). In addition, mice primed with both ears open, but tested with only one ear open, dropped with the blocked ear down (16 of 18 subjects with a clearly defined side of fall). This is the same asymmetry found in unilaterally tested $\mathrm{DBA} / 2 \mathrm{~J}$ mice.

Most seizures in mice of the $\mathrm{SJL} / \mathrm{J}$ strain were preceded by two running phases, one occurring before $30 \mathrm{sec}$ had elapsed and the other after more than $30 \mathrm{sec}$. As was true of mice of the $\mathrm{DBA} / 2 \mathrm{~J}$ strain, the biphasic bouts of running exhibited by $\mathrm{SJL} / \mathrm{J}$ mice were separated by a period of at least $10 \mathrm{sec}$ during which the subject groomed or remained essentially motionless. The relationship between the side of fall in the seizure and the directions of the running phases is presented in Table 2, which includes the data for mice that had at least one running episode with an identified direction and that fell to the left or right. Due to difficulty in unequivocally identifying the direction of a run in some instances, the totals for first and second runs in Table 2 are not always equal. The results indicate that $\mathrm{SJL} / \mathrm{J}$ mice undergo a reversal in asymmetry during a two-phase audiogenic seizure. Thus, SJL/J mice with seizures driven by the right ear begin circling clockwise during the first running phase, switch direction of running to counterclockwise (typically during either the pause between running phases or part of the way through the later running bout), and subsequently fall with the left side down. Since the point of the reversal in direction was somewhat variable, Table 2 is based upon the initial direction of the first running bout and the final direction of the second running bout.

Running bouts were not limited to subjects which subsequently seized. At least one running bout of an identifiable direction occurred in 30 of the DBA/2J subjects and 27 of the $\mathrm{SJL} / \mathrm{J}$ subjects that did not undergo an audiogenic seizure. Due to the limited number of subjects that underwent two running phases, no discernible pattern was noted for the directions of the runs that occurred more than $30 \mathrm{sec}$ after auditory stimulation began. The results indicate, however, that the direction of the initial run was the same in subjects that subsequently did not seize as it was for subjects that exhibited running bouts culminating in a convulsion.

\section{DISCUSSION}

In the present paper, we have examined the initiation and development of audiogenic seizures in two strains of mice and demonstrated that the burst(s) of

Table 2

Summary of the Relationships Between the Directions of Run and Side of Fall in Unilaterally and Bilaterally Tested SJL/J Mice, a Strain Requiring Sensitization

\begin{tabular}{|c|c|c|c|c|c|c|c|c|c|c|c|c|c|c|c|}
\hline & & \multicolumn{14}{|c|}{ Side of Fall } \\
\hline & & \multicolumn{4}{|c|}{ Right Ear Sensitized } & \multicolumn{4}{|c|}{ Left Ear Sensitized } & \multicolumn{6}{|c|}{ Both Ears Sensitized } \\
\hline & & \multicolumn{2}{|c|}{$\begin{array}{c}\text { Right Ear } \\
\text { Tested }\end{array}$} & \multicolumn{2}{|c|}{$\begin{array}{l}\text { Both Ears } \\
\text { Tested }\end{array}$} & \multicolumn{2}{|c|}{$\begin{array}{c}\text { Left Ear } \\
\text { Tested }\end{array}$} & \multicolumn{2}{|c|}{$\begin{array}{l}\text { Both Ears } \\
\text { Tested }\end{array}$} & \multicolumn{2}{|c|}{$\begin{array}{l}\text { Right Ear } \\
\text { Tested }\end{array}$} & \multicolumn{2}{|c|}{$\begin{array}{c}\text { Left Ear } \\
\text { Tested }\end{array}$} & \multicolumn{2}{|c|}{$\begin{array}{l}\text { Both Ears } \\
\text { Tested }\end{array}$} \\
\hline & & $\mathrm{L}$ & $\mathbf{R}$ & L & $\mathbf{R}$ & $\mathrm{L}$ & $\mathbf{R}$ & $\mathbf{L}$ & $\mathrm{R}$ & $\mathrm{L}$ & $\mathbf{R}$ & $\mathrm{L}$ & $\mathbf{R}$ & $\mathrm{L}$ & $\mathrm{R}$ \\
\hline \multirow{2}{*}{ DB 1} & $\mathrm{C}$ & 8 & 0 & 4 & 2 & 0 & 1 & 0 & 1 & 4 & 1 & 0 & 2 & 2 & 0 \\
\hline & $\mathrm{CC}$ & 4 & 0 & 1 & 0 & 0 & 4 & 0 & 3 & 0 & 1 & 0 & 5 & 1 & 3 \\
\hline \multirow{2}{*}{ DB2 } & $\mathrm{C}$ & 1 & 0 & 3 & 2 & 0 & 6 & 0 & 6 & 0 & 0 & 0 & 7 & 4 & 2 \\
\hline & $\mathrm{CC}$ & 13 & 0 & 2 & 0 & 0 & 1 & 0 & 0 & 5 & 1 & 0 & 2 & 7 & 4 \\
\hline \multirow{2}{*}{ DU } & C & 0 & 0 & 0 & 0 & 0 & 0 & 0 & 0 & 0 & 0 & 0 & 0 & 3 & 2 \\
\hline & $\mathrm{CC}$ & 0 & 0 & 2 & 0 & 0 & 0 & 1 & 0 & 0 & 0 & 0 & 0 & 4 & 4 \\
\hline
\end{tabular}

Note-L, $R$, and $B$ denote left, right, and both, respectively; $C$ and $C C$ represent clockwise and counterclockwise, respectively. The upper four rows of the table depict data for the two episodes of running observed during biphasic audiogenic seizures, those occurring after $30 \mathrm{sec}$ of auditory stimulation; $D B 1=$ direction of first run of biphasic seizure, and $D B 2=$ direction of second run of biphasic seizure. The bottom two rows of the table present data for the few $S J L / J$ mice that exhibited uniphasic audiogenic seizures, those occurring within 30 sec of auditory stimulation; $D U=$ direction of run of uniphasic seizure. 
running preceding seizures are predictably asymmetric. Furthermore, the progression of asymmetric motor patterns in unilaterally stimulated subjects was found to differ between the strains tested. Both $\mathrm{DBA} / 2 \mathrm{~J}$ and $\mathrm{SJL} / \mathrm{J}$ mice exhibited similar asymmetries during the burst of running immediately before the clonic stage of seizures preceded by two runs. SJL/J mice, however, undergo a reversal of asymmetry between the two episodes of running, a reversal which does not occur in the DBA/ $2 \mathrm{~J}$ strain. This reversal suggests that there may be a qualitative difference in the development, as well as elicitation, of audiogenic seizures between mice requiring prior auditory stimulation in order to become susceptible to convulsions and those not requiring such stimulation.

For many years there has been a concern among workers as to whether the running phase of an audiogenic seizure is an essential part of the emerging convulsive sequence or whether it might primarily subserve an unrelated function, such as an attempt to escape from sound. It has proven difficult to resolve this question in ways that avoid a dramatic insult to the organism or that do not interfere with the seizure sequence. For example, a reduction of seizure severity when mice are physically restrained has been reported (Willott, 1974); however, it has also been shown by Willott (1977) that electrographic evidence of seizure can be obtained in curarized mice exposed to auditory stimulation. This suggests that it is possible to induce an audiogenic seizure in the absence of overt running components. Our results, obtained by studying unilaterally sensitive mice, lead us to conclude that the running episodes so characteristic of audiogenic seizure are indeed an integral part of the fabric of the emerging convulsion. These running episodes are modulated in an asymmetrical manner that is strictly related to the experimentally controlled asymmetries of auditory input and, when a convulsion occurs, to the asymmetries of output that are observed during the clonic-tonic phase of seizure.

The demonstration that all stages of audiogenic seizure are asymmetric and are related in a predictable sequence leads us to believe that a continuing examination of asymmetries of uniphasic and biphasic seizures may be essential to our understanding further the physiological processes underlying audiogenic seizure. This conviction was recently reinforced by the finding that unilateral lesions of the amygdala eliminate the reversal of running direction that is characteristic of biphasic seizure in SJL/J mice (Reid \& Weiss, 1980).

\section{REFERENCE NOTE}

1. Reid, H. M., \& Weiss, C. Effect of amygdala lesions upon sound-induced seizures in mice. Paper presented at the American Psychological Association Convention, Montreal, 1980.

\section{REFERENCES}

Collins, R. L. Audiogenic seizures. In D. P. Purpura, J. K. Penry, D. B. Tower, D. M. Woodbury, \& R. D. Walter (Eds.), Experimental models of epilepsy-A manual for the laboratory worker. New York: Raven Press, 1972.

Fulle R, J. L., \& Collins, R. L. Temporal parameters of sensitization for audiogenic seizures in $\mathrm{SJL} / \mathrm{J}$ mice. Developmental Psychobiology, 1968, 1, 185-188. (a)

Fuller, J. L., \& Collins, R. L. Mice unilaterally sensitized for audiogenic seizure. Science, 1968, 162, 1295. (b)

Fuller, J. L., \& Smith, M. E. Kinetics of sound induced convulsions in some inbred mouse strains. American Journal of Physiology, 1953, 172, 661-670.

HenRY, K. R. Audiogenic seizure susceptibility induced in C57BL/ 6J mice by prior auditory exposure. Science, 1967, 158, 938-940.

Iturhian, W. B., \& Fink, G. B. Influence of age and brief auditory conditioning upon experimental seizures in mice. Developmental Psychobiology, 1969, 2, 10-18.

Schreiber, R. A., Lehmann, A., Ginsberg, B. E., \& Fuller, J. L. Development of susceptibility to audiogenic seizures in $\mathrm{DBA} / 2 \mathrm{~J}$ and $\mathrm{Rb}$ mice: Toward a systematic nomenclature of audiogenic seizure levels. Behavior Genetics, 1980, 10, 537-543.

WARD, R. Recovery of susceptibility after audiogenic seizure. Nature New Biology, 1971, 233, 56-57.

WARD, R., \& Collins, R. L. Asymmetric audiogenic seizures in mice: A possible analogue of focal epilepsy. Brain Research, 1971, 31, 207-210.

Willot, J. F. Protection from lethal audiogenic seizures in mice by physical restraint of movement. Experimental Neurology: 1974, 43, 359-368.

WiLlotT, J. F. Audiogenic seizures in curarized mice. Journal o Comparative and Physiological Psychology, 1977, 91, 937-941.

(Manuscript received November 20, 1981; revision accepted for publication May 4, 1982.) 